\title{
General surgery in Canada: current scope of practice and future needs
}

\author{
Travis Schroeder, MD \\ Caroline Sheppard, PhD \\ Dawn Wilson \\ Caitlin Champion, MD, MSc \\ Shanna DiMillo, MBNF \\ Roy Kirkpatrick, MD \\ Stephen Hiscock, MD \\ Randall Friesen, MD \\ Lauren Smithson, MPhil, MD \\ Peter Miles, MD
}

Accepted Dec. 5, 2019

\section{Correspondence to: \\ P. Miles \\ Queen Elizabeth II Hospital \\ $1040998 \mathrm{St}$ \\ Grande Prairie AB T8V 2E8 \\ pkabmiles@gmail.com}

DOI: $10.1503 /$ cjs.004419
Background: The scope of practice of general surgeons in Canada is highly variable. The objective of this study was to examine the demographic characteristics of general surgeons in Canada and compare surgical procedures performed across community sizes and specialties.

Methods: Data from the Canadian Institute for Health Information's National Physician Database were used to analyze fee-for-service (FFS) care provided by general surgeons and other providers across Canada in 2015/16.

Results: Across 8 Canadian provinces, 1669 general surgeons provided FFS care. The majority of the surgeons worked in communities with more than 100000 residents $(71 \%)$, were male $(78 \%)$, were aged $35-54$ years $(56 \%)$ and were Canadian medical graduates $(76 \%)$. Only $7 \%$ of general surgeons practised in rural areas and $14 \%$ in communities with between 10000 and 50000 residents. Rural communities were significantly more likely to have surgeons who were international medical graduates or who were older than 65 years. The surgical procedures most commonly performed by general surgeons were hernia repairs, gallbladder and biliary tree surgery, excision of skin tumours, colon and intestine resections and breast surgery. Many general surgeons performed procedures not listed in their Royal College of Physicians and Surgeons of Canada training objectives.

Conclusion: Canadian general surgeons provide a wide array of surgical services, and practice patterns vary by community size. Surgeons practising in rural and small communities require proficiency in skills not routinely taught in general surgery residency. Opportunities to acquire these skills should be available in training to prepare surgeons to meet the care needs of Canadians.

Contexte : La pratique des chirurgiens généralistes au Canada varie grandement. Cette étude visait à examiner les caractéristiques démographiques des chirurgiens généralistes au Canada et à comparer les interventions réalisées selon la spécialité et la taille des collectivités.

Méthodes : Des données de la Base de données nationale sur les médecins de l'Institut canadien d'information sur la santé ont été utilisées pour analyser les soins rémunérés à l'acte dispensés par des chirurgiens généralistes et d'autres fournisseurs de soins au Canada en 2015-2016.

Résultats : Dans 8 provinces canadiennes, 1669 chirurgiens généralistes ont fourni des soins rémunérés à l'acte. La majorité d'entre eux travaillaient dans des collectivités de plus de 100000 résidents (71\%), étaient des hommes (78\%), avaient entre 35 et 54 ans $(56 \%)$ et avaient obtenu leur diplôme de médecine au Canada (76 \%). Seuls $7 \%$ des chirurgiens généralistes travaillaient en région rurale et $14 \%$, dans des collectivités comptant entre 10000 et 50000 résidents. En région rurale, la probabilité que les chirurgiens soient des diplômés internationaux en médecine ou aient plus de 65 ans était significativement plus élevée. Les interventions les plus fréquentes étaient la réparation d'une hernie, la chirurgie de la vésicule biliaire et des voies biliaires, le retrait de tumeurs de la peau, la résection du côlon ou de l'intestin et la chirurgie mammaire. De nombreux chirurgiens généralistes ont réalisé des procédures ne faisant pas partie des objectifs de formation du Collège royal des médecins et chirurgiens du Canada.

Conclusion : Les chirurgiens généralistes canadiens réalisent une large gamme d'interventions chirurgicales et leur pratique varie selon la taille de la collectivité dans laquelle ils travaillent. Les chirurgiens exerçant en milieu rural et dans les petites 
collectivités doivent avoir des compétences qui ne sont habituellement pas enseignées durant la résidence en chirurgie générale. La formation devrait intégrer des occasions d'acquérir ces compétences pour préparer les chirurgiens à répondre aux besoins en matière de soins des Canadiens.

T he scope of practice of general surgeons in Canada is highly variable. ${ }^{1}$ Despite having vastly different practice profiles, all graduates must meet the training objectives set forth by the Royal College of Physicians and Surgeons of Canada. ${ }^{2,3}$ With trends toward increased subspecialty training, there is concern that the true "generalist surgeon" is a dying breed and that the supply of new graduates will be insufficient to replace the general surgeons who are retiring in small communities. ${ }^{4}$ In rural communities dependent on a small number of aging surgeons, the retirement of general surgeons may force hospitals to close or to discontinue offering certain procedures if adequately trained new graduates are not able to replace them. ${ }^{5}$ Concerns have been raised that low case volumes for rural general surgeons may lead to worse outcomes, although the generalizability of the volume-outcome relationship to rural settings has been questioned. ${ }^{6,7}$ Furthermore, if outcomes were worse in rural centres, many patients would still prefer to have their operation done locally, accepting higher risks of complications and even mortality. ${ }^{8,9}$ Lack of broad-based training, lifestyle issues, decreased interest in surgery among medical graduates, inadequate compensation and increased expectations of the public are but some of the barriers to recruiting rural surgeons. ${ }^{10,11}$ In an attempt to broaden the surgical skills of graduates, some North American programs have begun offering rural surgery fellowships. ${ }^{12}$

Gaps in access to emergency surgical care disproportionately affect underserved and rural communities. ${ }^{13,14}$ To address these gaps, several Western Canadian programs have offered enhanced surgical skills training to general practitioners. ${ }^{15}$ Prior studies have outlined the markedly different operative experience of providers in rural hospitals compared with large urban centres and have recommended that graduating residents intending to practise in rural settings receive a broader training experience than their urban colleagues. ${ }^{16-19}$ In a retrospective review of case logs, Sticca and colleagues argued that optimal training for rural surgery practice should include experience in obstetrics and gynecology, orthopedics, urology and otolaryngology. ${ }^{20}$ Procedures in these specialties are usually taught outside of residency by senior colleagues. ${ }^{21}$ Not surprisingly, many graduates pursuing a rural or small community practice are uncomfortable with many of these specialty procedures and feel ill prepared to replace existing surgeons. ${ }^{22}$ Many small communities benefit from visiting locum general surgeons or other surgical specialists who provide elective services, such as joint arthroplasty or tonsillectomy, on a scheduled basis. Defining changes in general surgery practice patterns by community size could help better inform residency training objectives, prepare surgeons for their career and meet the needs of the community. The objectives of this study were to analyze the demographic characteristics of general surgeons practising in Canada, to stratify the procedures they performed by community population size and by the surgical procedures lists in the Royal College's objectives of training for general surgery, and to compare the practice patterns of general surgeons with those of other specialists.

\section{Methods}

\section{Data acquisition}

The National Physician Database (NPDB) of the Canadian Institute for Health Information (CIHI) was used to analyze fee-for-service (FFS) care provided by general surgeons and other providers in the most recent available federal fiscal year (Apr. 1, 2015, to Mar. 31, 2016).

Data were available for 8 provinces (Newfoundland and Labrador, Nova Scotia, New Brunswick, Ontario, Manitoba, Saskatchewan, Alberta and British Columbia). The Northwest Territories and Nunavut were excluded as physician-level data were not available for these jurisdictions. Prince Edward Island and Yukon were excluded as future research based on the requested data may cover multiple years for which these jurisdictions did not submit data. Data for Quebec could not be shared for this study because of an agreement between the government of Quebec and CIHI. Only FFS billing data were used; alternative forms of reimbursement (e.g., salary, private billing or capitation) were excluded. Reciprocal billing payments were included. Physicians were separated by discipline on the basis of payment plan specialty, and billings were adjusted to prevent billing overlap. General surgeon demographic information was available from CIHI through the NPDB.

This study did not require ethics approval as it did not include identifiable patient information, and results based on this data source are published in the public domain. Data were securely housed on the Royal College server in Ottawa, Ontario.

\section{Data stratification}

Communities were grouped into 4 categories of population size, in line with Statistics Canada definitions: areas with more than 100000 residents, areas with between 
50000 and 100000 residents, areas with between 10000 and 50000 residents, and rural areas. Rural areas were defined as areas outside commuting distance from an urban centre with more than 10000 residents. It was not possible to stratify data by province, because of CIHI's deidentifying data collection methods. See Appendix 1 (available at canjsurg.ca/004419-a1) for more information on Statistics Canada community groupings.

Procedures were stratified by the surgical procedures lists in the Royal College's objectives of training for general surgery. For procedures in category A, "on completion of training, general surgery residents must have expert knowledge of the ... procedures, including their indications, contraindications, alternative treatment options, and more common complications. The graduate must be competent to independently perform these procedures and to provide appropriate perioperative care." ${ }^{2}$

For procedures in category B, "on completion of training, general surgery residents must understand the ... procedures, including the indications, contraindications, alternative treatment options, and more common complications. The graduate may be able to perform these procedures independently."

For procedures in category $\mathrm{C}$, "on completion of training, general surgery residents will be able to describe the principles of the ... procedures, indications for referral, perioperative management, and complications. The graduate is not expected to be able to perform these procedures without further training."

\section{Inclusion and exclusion criteria}

The procedures in the following CIHI categories were included in the study: fractures; cardiac electrophysiology (pacemaker insertion); varicose vein repair; colon and intestines - colectomy; rectum, proctectomy and anus; appendectomy; laparotomy; gallbladder and biliary tract; tonsillectomy; hernia repair; gastroscopy, colonoscopy and sigmoidoscopy; hysterectomy; sterilization; vasectomy; mastectomy and breast surgery; breast tumour excision and biopsy; incision of abscess; removal of foreign body; excision of tumour; suture of wound; excision of nail; cesarean section; service at delivery; other obstetrical services; and dilatation and curettage (see Appendix 1, Table S1, for the definitions of these CIHI categories).

Procedures in the following CIHI categories were excluded from the study: minor fractures, other musculoskeletal, other respiratory, coronary angioplasty, other heart and pericardium, carotid endarterectomy, other cardiovascular, other digestive, bronchoscopy and laryngoscopy, other endoscopy, other female genital system, other eye and ear, urinary system, other male genital system, other integumentary, other minor surgery, and cystoscopy.

\section{Outcome}

The primary outcome of this study was the number and types of procedures performed by general surgeons. This outcome was stratified by community population size and by the surgical procedures lists in the Royal College's objectives of training for general surgery across locations, and it was also used to compare the practice patterns of general surgeons with those of other specialists.

\section{Statistical analysis}

Descriptive statistics were used and a Fisher exact $\chi^{2}$ test with pairwise comparison and Bonferroni correction was applied. To counteract the high sample size, Cramer $V$ and $\varphi$ were used to measure the level of association. Tabular data were described as counts and percentages. Stata 14 software was used for analysis. Procedures with 5 or fewer instances were not recorded in the database, and a conservative estimate of 1 was used in the analysis.

\section{Results}

\section{Demographic characteristics}

In 2015/16, 53727 physicians provided FFS care in Canada across 8 provinces, of whom 1669 were general surgeons. In 2018 there were 2241 general surgeons practising in Canada. ${ }^{23}$ Most of the surgeons worked in communities with a population greater than 100000 residents, were men (78\%), were aged $35-54$ years $(56 \%)$ and were Canadian medical graduates (76\%) (Table 1 and Fig. 1).

\begin{tabular}{|c|c|c|c|c|c|c|c|c|c|}
\hline \multirow[b]{3}{*}{ Community category } & \multicolumn{9}{|c|}{ No. $(\%)$ of general surgeons } \\
\hline & \multicolumn{2}{|c|}{$\begin{array}{c}\text { Sex } \\
n=1635\end{array}$} & \multicolumn{5}{|c|}{$\begin{array}{c}\text { Age, } y r \\
n=1635\end{array}$} & \multicolumn{2}{|c|}{$\begin{array}{l}\text { Location of medical education } \\
\qquad n=1625\end{array}$} \\
\hline & Male & Female & $<35$ & $35-44$ & $45-54$ & $55-65$ & $>65$ & Canada & Other \\
\hline > 100000 residents & $919(77)$ & $270(23)$ & $125(11)$ & 375 (32) & $318(27)$ & $224(19)$ & $147(12)$ & $958(81)$ & $224(19)$ \\
\hline 50 000-100 000 residents & $77(80)$ & $19(20)$ & $10(10)$ & $25(26)$ & $28(29)$ & $18(19)$ & $15(16)$ & $79(82)$ & $17(18)$ \\
\hline $10000-50000$ residents & $187(82)$ & $41(18)$ & $19(8)$ & $60(26)$ & $53(23)$ & $54(24)$ & $42(18)$ & $140(62)$ & $86(38)$ \\
\hline Rural & $99(81)$ & $23(19)$ & $14(11)$ & $33(27)$ & $24(20)$ & $19(16)$ & $32(26)$ & $72(60)$ & $49(40)$ \\
\hline
\end{tabular}




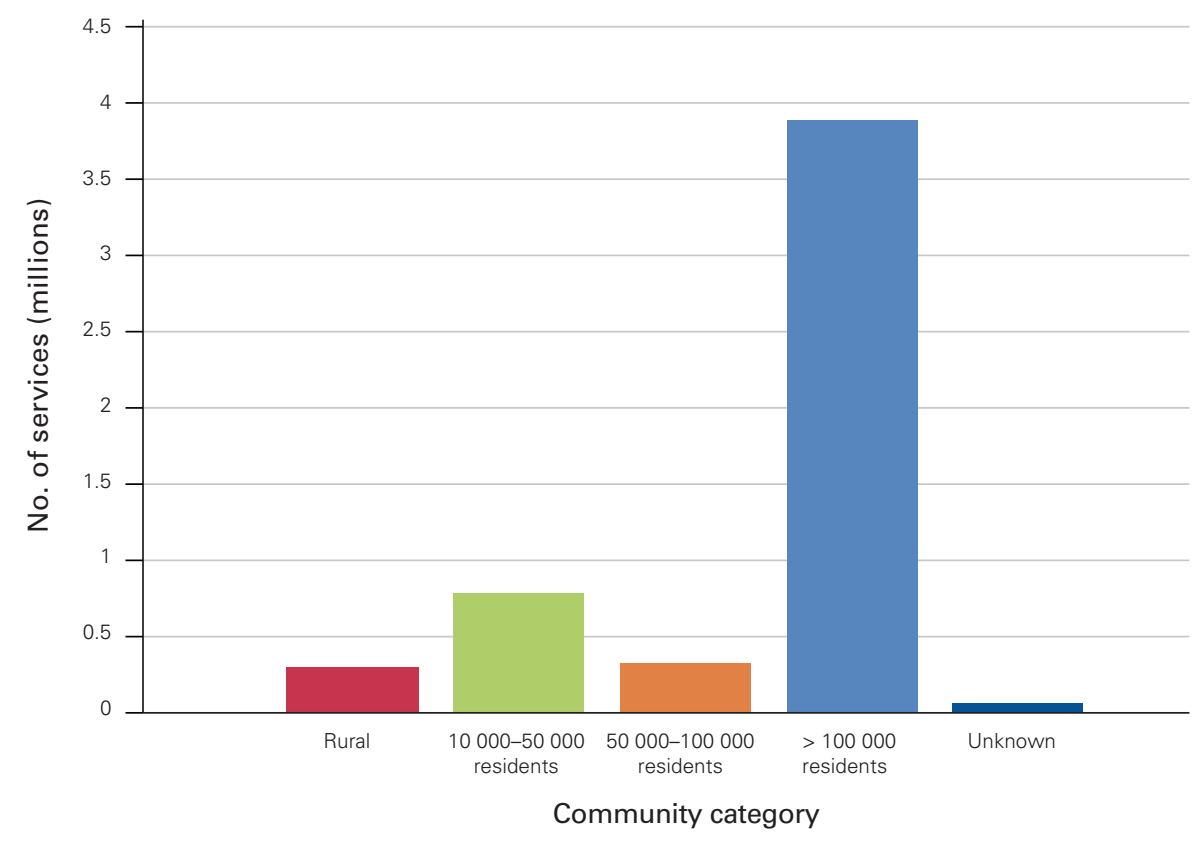

Fig. 1. Number of services (in millions) provided by general surgeons in 2015/16 by community category.

In Table 1 the demographic characteristics of general surgeons are reported by community population size. The proportion of male to female general surgeons did not vary by geographic region $(p=0.34)$. There was a significant difference in general surgeon age by population size $(p=0.005)$. There was no difference for surgeons younger than 35 years of age and those aged 35-44 years $(p=0.85)$. Rural communities had significantly more general surgeons older than 65 years of age than communities with more than 100000 residents $(p<0.001)$. There was also a significantly higher proportion of international medical graduates in rural areas and communities with 10000 50000 residents than in communities with more than 50000 residents $(p<0.001)$.

\section{General surgery practice}

General surgeons provided Canadians with 5.39 million services during the study period. Services were distributed almost equally among female and male patients (51\% v. $49 \%)$. Fifty-seven percent of the care provided by general surgeons was for patients aged 25-64 yr and $38 \%$ was for seniors (aged $\geq 65 \mathrm{yr}$ ). Seventy-three percent (3.91 million) of the services provided by general surgeons occurred in communities with a population greater than 100000 (Fig. 1).

The most commonly performed surgical procedures by general surgeons were hernia repair (70610 services), gallbladder and biliary tract procedures (56320 services), excision of skin tumours (46148 services), procedures involving the colon and intestines (40158 services) and mastectomy and other procedures involving the breast (28177 services).

In smaller communities, the fifth most common surgical procedure was appendectomy (in areas with populations of $50000-100000$ ) and incision of abscesses (in rural areas and areas with populations of $10000-50000)$. Across all communities both colonoscopy $(n=503445)$ and gastroscopy $(n=172402)$ were the most commonly performed procedures by general surgeons.

Procedures were further stratified by the surgical procedures lists in the Royal College's objectives of training for general surgery (Table 2, Table 3, Table 4). No surgical procedures from list $\mathrm{C}$ were identified in the data. General surgery practice (proportion of each procedure performed) differed significantly by community size (see Appendix 1, Table S6); however, these differences were all very weak associations according to the Cramer $V$ and $\varphi$.

\section{Practice patterns of general surgeons versus other specialists}

\section{Gastrointestinal procedures}

General surgeons performed more gastrointestinal procedures in rural communities than general practitioners (Fig. 2).

\section{Integumentary procedures}

The proportion of integumentary procedures performed by the different types of specialists varied significantly by 
Table 2. Surgical procedures in list A of the Royal College of Physicians and Surgeons of Canada's objectives of training for general surgery, performed by general surgeons in 2015/16*

\begin{tabular}{|c|c|c|c|c|c|}
\hline \multirow[b]{2}{*}{ Procedure } & \multicolumn{5}{|c|}{ No. $(\%)$ of procedures } \\
\hline & Rural & $\begin{array}{c}10000-50000 \\
\text { residents }\end{array}$ & $\begin{array}{c}50000-100000 \\
\text { residents }\end{array}$ & $\begin{array}{l}>100000 \\
\text { residents }\end{array}$ & Unknowr \\
\hline Laparotomy & $164(4)$ & 411 (9) & $306(7)$ & 3465 (79) & $18(<1)$ \\
\hline Appendectomy & $1010(4)$ & $2855(12)$ & $1781(7)$ & $18520(76)$ & $162(1)$ \\
\hline Colon and intestines (colectomy) & $1304(3)$ & $4567(11)$ & $2565(6)$ & 31585 (79) & $137(<1)$ \\
\hline Rectum, proctectomy, anus & $831(4)$ & $2458(11)$ & $1372(6)$ & $17913(78)$ & $322(1)$ \\
\hline Gallbladder, biliary tract & $2823(5)$ & 7756 (14) & $4198(7)$ & 41042 (73) & $501(1)$ \\
\hline Hernia repair & $3608(5)$ & $9982(14)$ & $4971(7)$ & $51273(73)$ & $776(1)$ \\
\hline Mastectomy and breast surgery & $837(3)$ & $2220(8)$ & $1463(5)$ & $23413(83)$ & $244(1)$ \\
\hline Breast tumour excision, biopsy & $399(5)$ & 1037 (13) & $745(9)$ & $5842(72)$ & $71(1)$ \\
\hline Incision of abscess & $1188(7)$ & $3423(20)$ & $847(5)$ & $11777(68)$ & $188(1)$ \\
\hline Removal of foreign body & $227(11)$ & $496(24)$ & $223(11)$ & $1082(53)$ & $18(1)$ \\
\hline Excision of tumour & $6362(14)$ & $11317(25)$ & $3382(7)$ & $24120(52)$ & $967(2)$ \\
\hline Suture of wound & 819 (8) & $1428(15)$ & $1139(12)$ & $6302(64)$ & $95(1)$ \\
\hline Excision of nail & 1008 (13) & $1744(23)$ & $584(8)$ & $4199(54)$ & $178(2)$ \\
\hline Gastroscopy & $16067(9)$ & $41269(24)$ & $14804(9)$ & $97331(56)$ & $2931(2)$ \\
\hline Colonoscopy & $37536(7)$ & $98854(20)$ & $36689(7)$ & $323528(64)$ & $6838(1)$ \\
\hline Sigmoidoscopy $\dagger$ & $953(1)$ & $4033(6)$ & $2363(4)$ & 57180 (88) & $299(<1)$ \\
\hline \multicolumn{6}{|c|}{$\begin{array}{l}\text { *For procedures in list } \mathrm{A} \text {, graduates of general surgery residency programs "must have expert knowledge of the ... procedures, including their indications, contraindications, } \\
\text { alternative treatment options, and more common complications. The graduate must be competent to independently perform these procedures and to provide appropriate } \\
\text { perioperative care." } \\
\text { †Sigmoidoscopy is not listed in the Royal College of Physicians and Surgeons of Canada's objectives of training for general surgery. }{ }^{2}\end{array}$} \\
\hline
\end{tabular}

Table 3. Surgical procedures in list B of the Royal College of Physicians and Surgeons of Canada's objectives of training for general surgery, performed by general surgeons in 2015/16*

\begin{tabular}{lcccc} 
& & No. (\%) of procedures \\
\cline { 2 - 4 } Procedure & Rural & $\begin{array}{c}10 \text { 000-50 } 000 \\
\text { residents }\end{array}$ & $\begin{array}{c}50000-100000 \\
\text { residents }\end{array}$ & $\begin{array}{c}>100 \\
\text { residents }\end{array}$ \\
\hline Varicose vein repair & $352(5)$ & $1025(15)$ & $483(7)$ & 4978 (72) \\
\hline *For procedures in list B, graduates of general surgery residency programs "must understand the ... procedures, including the indications, contraindications, \\
alternative treatment options, and more common complications. The graduate may be able to perform these procedures independently."
\end{tabular}

Table 4. Surgical procedures in list $\mathbf{C}$ of the Royal College of Physicians and Surgeons of Canada's objectives of training for general surgery, performed by general surgeons in 2015/16*

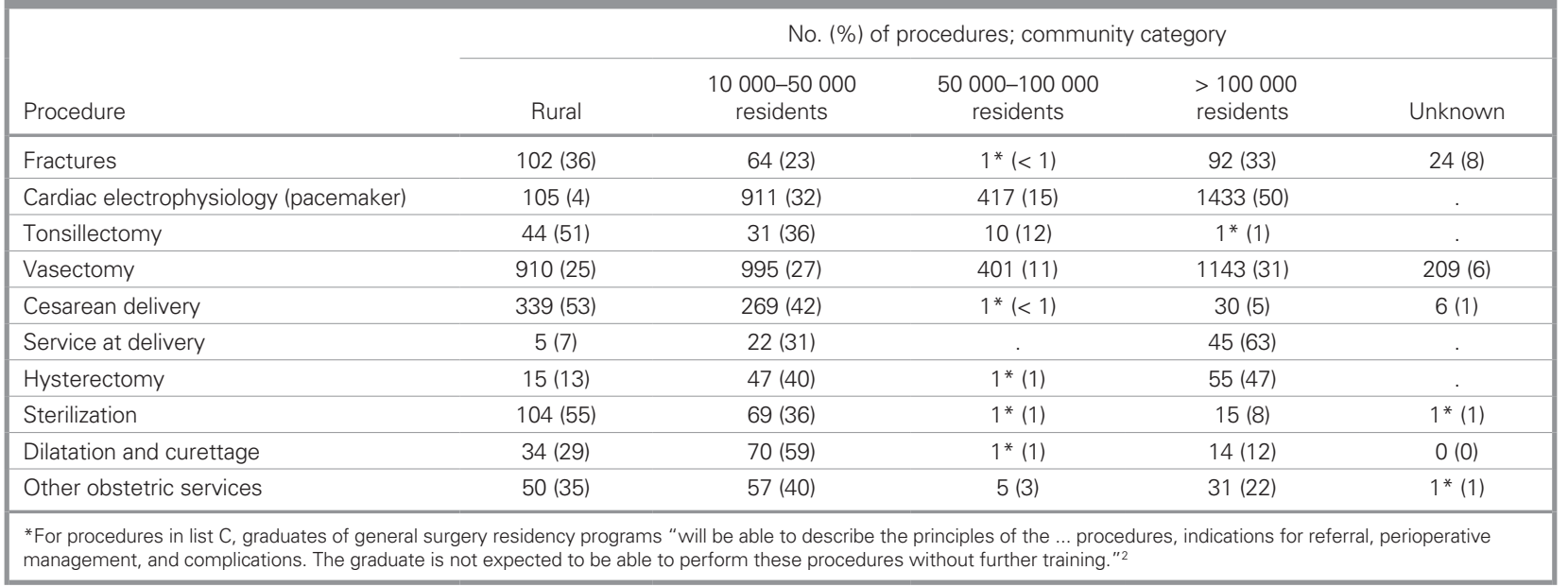

community size $(p<0.001$, Cramer $V=0.13$ weak), with the exception of the proportion of procedures performed by general practitioners and plastic surgeons in commun- ities with 50000-100000 residents $(p=0.40)$. Figure 3 shows the number of integumentary procedures by specialty and community size, with moderate $(\varphi=0.20-0.29)$ 


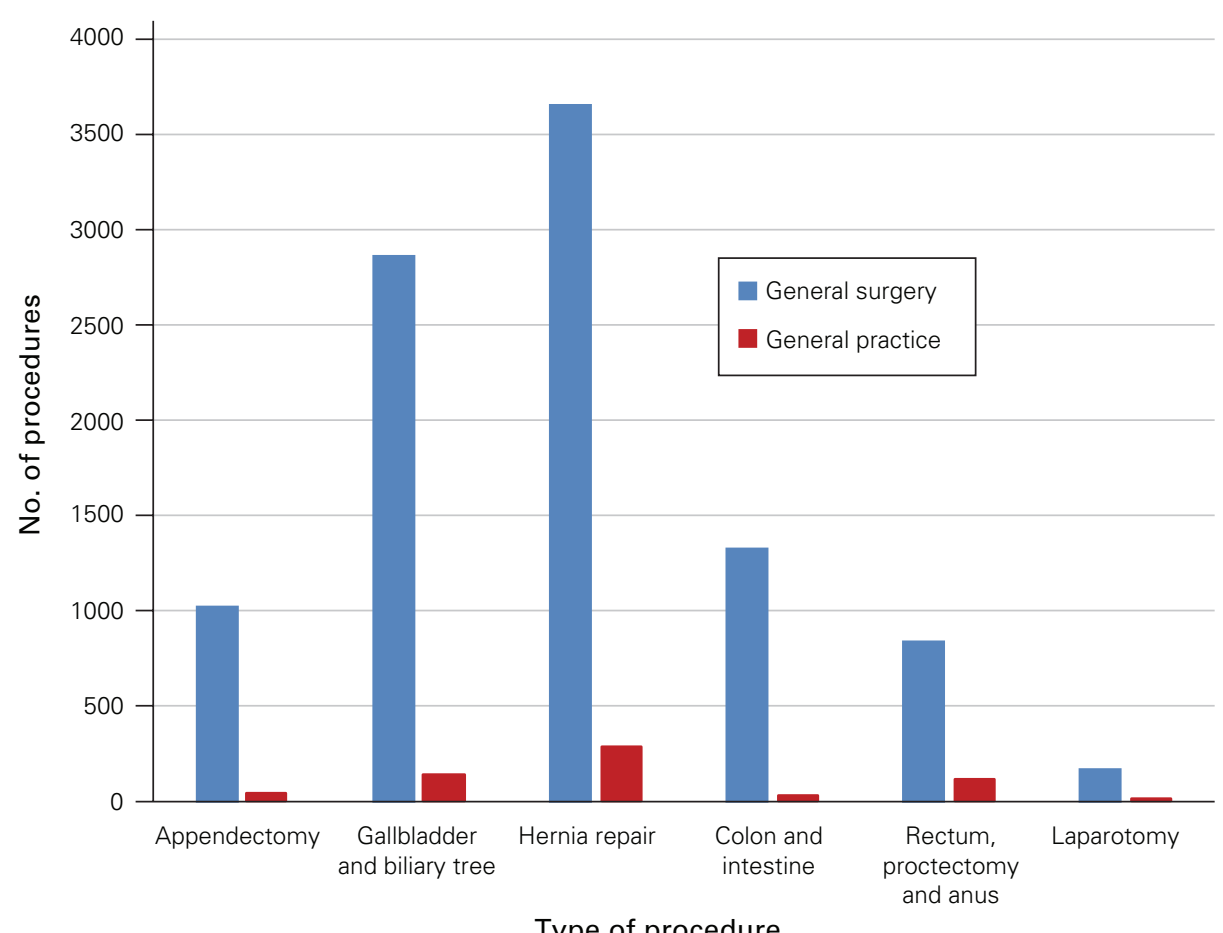

Type of procedure

Fig. 2. Number of gastrointestinal surgical procedures performed by general surgeons and general practitioners in rural communities in 2015/16.

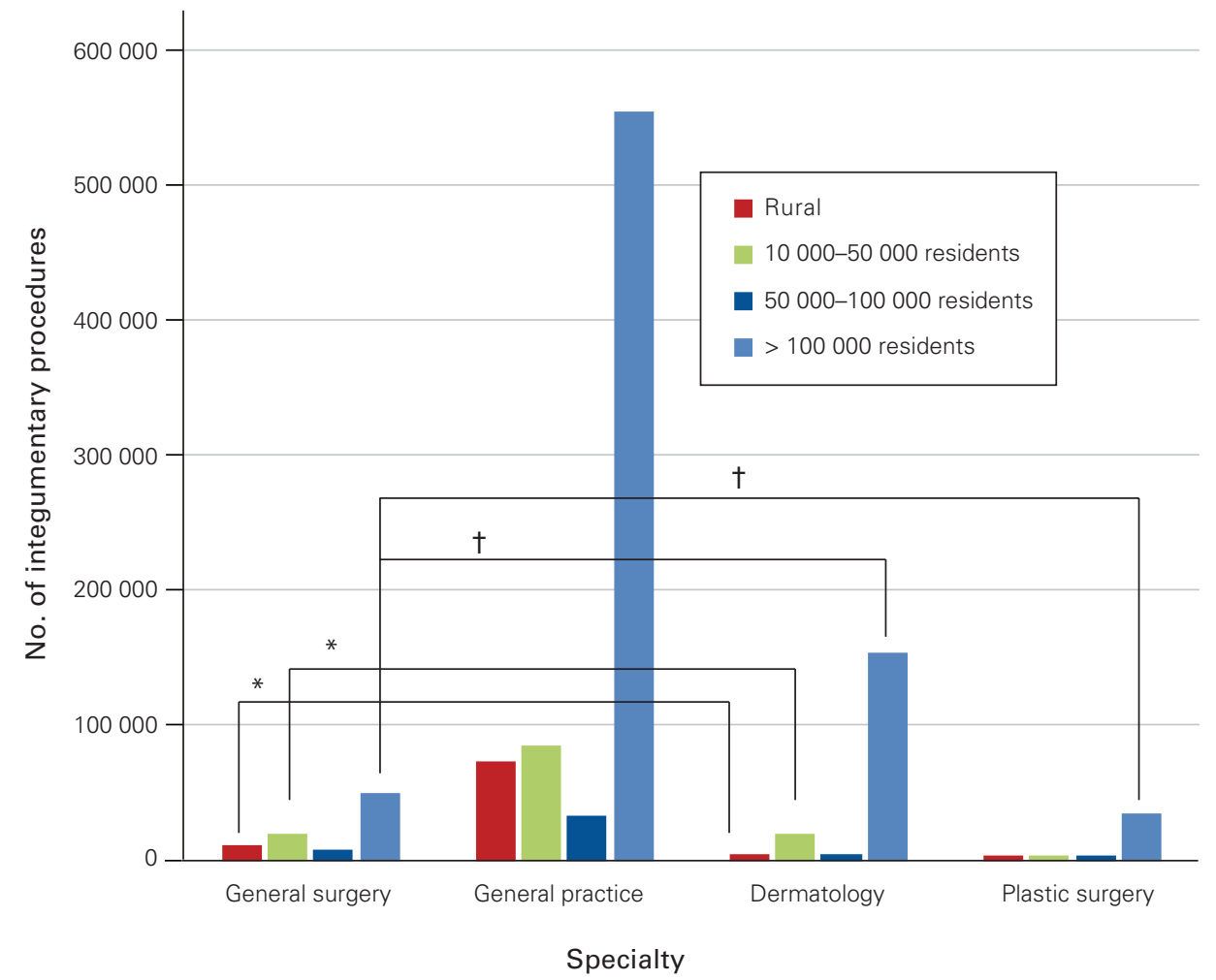

Fig. 3. Number of integumentary surgical procedures performed by general surgeons, general practitioners, dermatologists and plastic surgeons in $2015 / 16$, by community category. ${ }^{*}$ Moderate association; †strong association. 
to strong $(\varphi=0.30-0.40)$ associations between the proportions of procedures performed by specialty.

\section{Endoscopic procedures}

Specialists in internal medicine provided the majority of gastroscopies in communities with populations greater than 100000 , with a trend toward general surgeons as the practice location became more rural. There was a significant difference in the proportion of colonoscopies $(p<$ 0.0001 , Cramer $V=0.27$ moderate) and gastroscopies $(p<0.0001$, Cramer $V=0.28$ moderate) performed by the different types of specialists based on community size. Figure 4 and Figure 5 show the number of colonoscopies and gastroscopies by specialty and community size, with moderate $(\varphi=0.20-0.29)$ to very strong $(\varphi=0.35-0.40)$ associations between proportion of procedures performed by specialty.

\section{Procedures to treat fractures}

Orthopedic surgeons $(72.6 \%, n=101032)$ and general practitioners $(17.2 \%, n=23928)$ performed most of the fracture reductions or fixations in communities with populations greater than 50000 . In communities with fewer than 50000 residents, most of the orthopedic procedures were performed by orthopedic surgeons $(75.5 \%$, $n=13339)$ and general practitioners $(20.1 \%, n=3555)$; only $0.9 \%(n=166)$ were performed by general surgeons.
General surgeons who performed these services in communities with fewer than 50000 residents were significantly older $(61 \%[n=102]$ aged $>65 \mathrm{yr}, 39 \%[n=64]$ aged $<65 \mathrm{yr}, p<0.001)$ than the surgeons in larger communities $(99 \%[n=92]$ aged $<65 \mathrm{yr})$.

\section{Cardiac electrophysiologic (pacemaker) procedures}

General surgeons performed significantly more pacemaker insertions in rural communities than internal medicine specialists or thoracic surgeons $(p<0.001$, Cramer $V=0.20$ moderate). Figure 6 shows the number of cardiac electrophysiologic procedures by specialty and community size.

\section{Tonsillectomy}

The majority of tonsillectomies were performed by otolaryngologists and general practitioners in all communities. As with the findings for fracture management, general surgeons who did perform this procedure in rural communities were more likely to be older than 65 years of age $(p<0.001)$.

\section{Obstetric procedures}

With the exception of cesarean deliveries and sterilization procedures, general surgeons did not play a substantial role in obstetric care (i.e., service at delivery, hysterectomy, dilation and curettage, and other obstetric services).

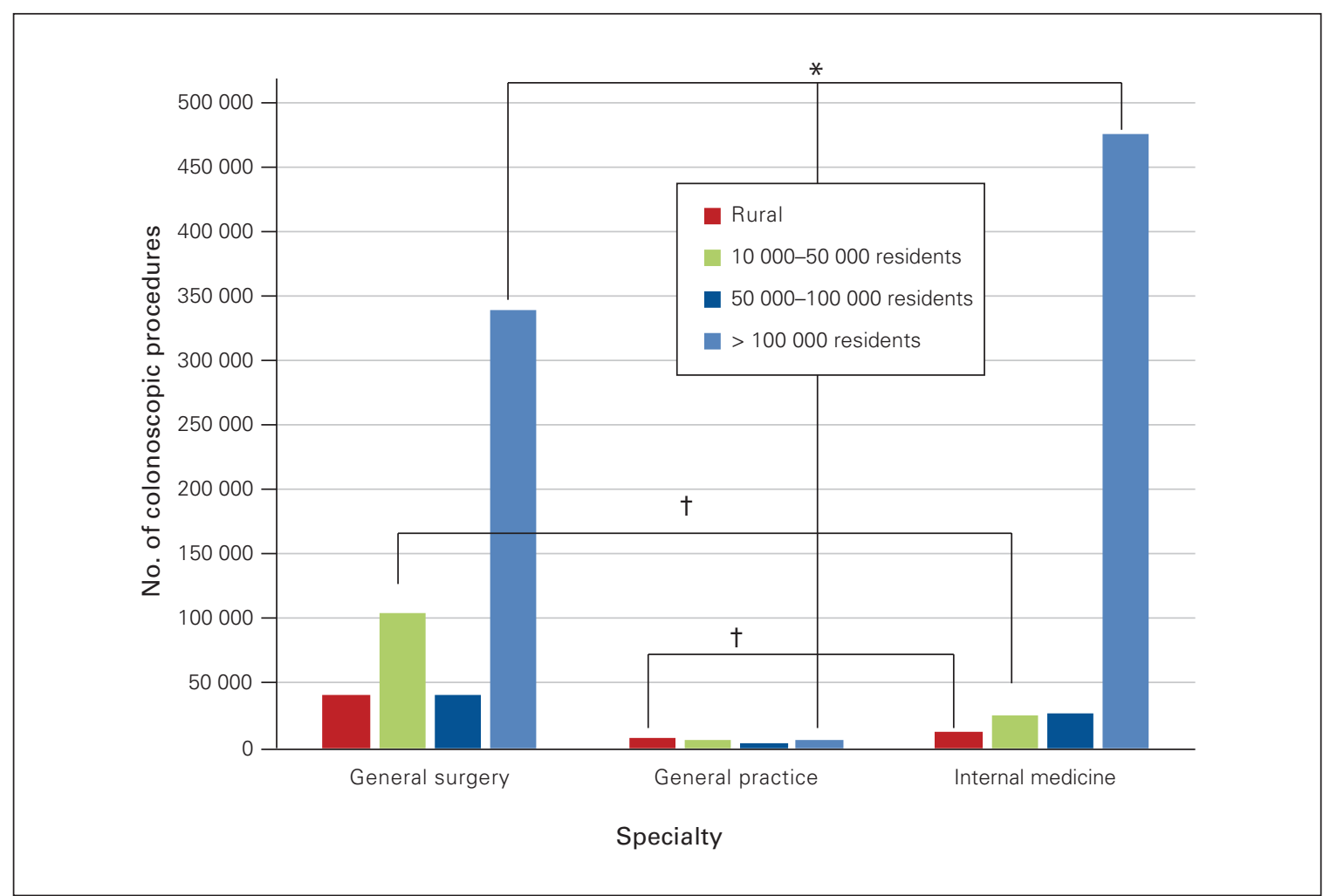

Fig. 4. Number of colonoscopies performed by general surgeons, general practitioners and internal medicine specialists, in 2015/16, by community category. ${ }^{*}$ Moderate association; †strong association. 


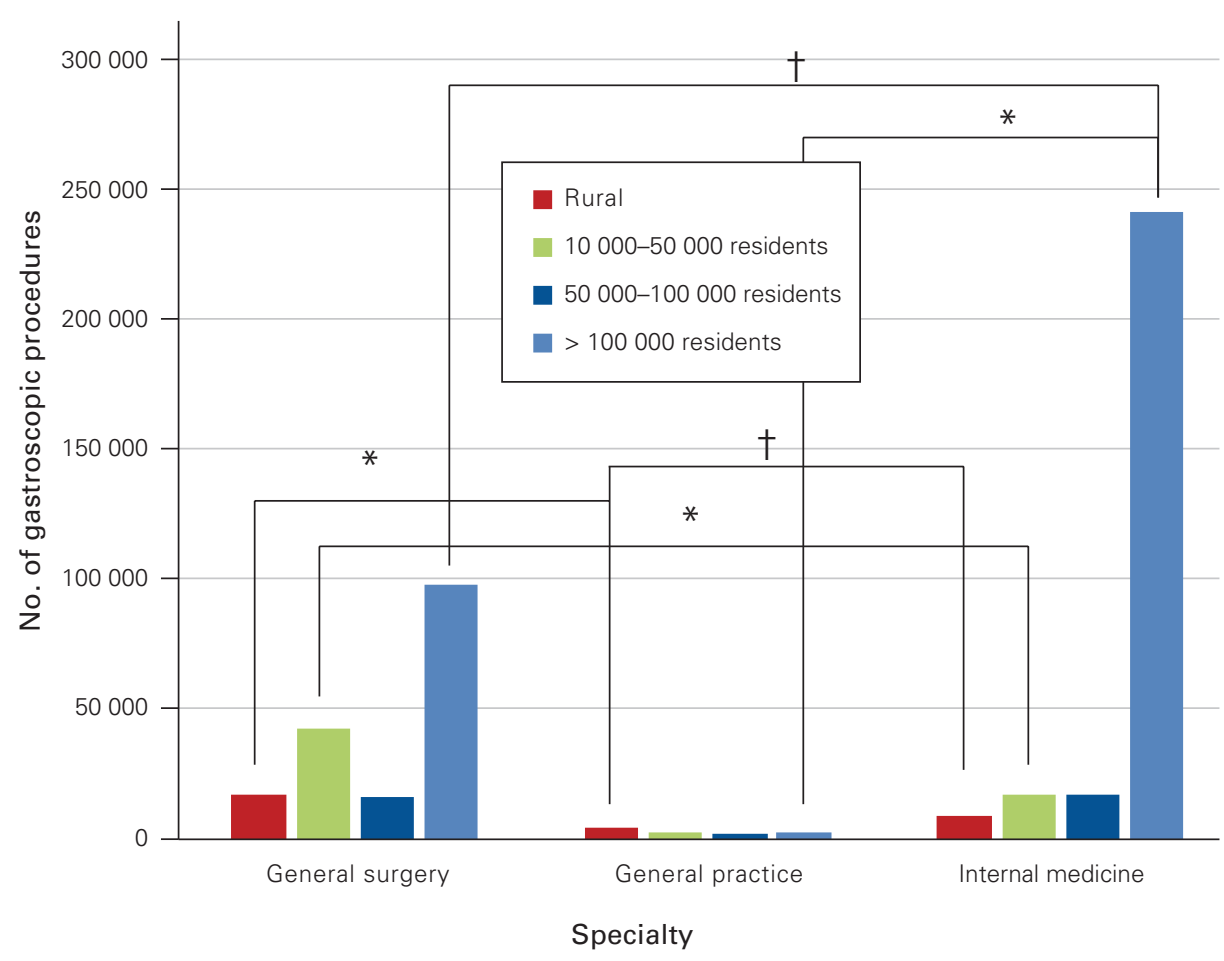

Fig. 5. Number of gastroscopies performed by general surgeons, general practitioners and internal medicine specialists in 2015/16, by community category. * Moderate association; †strong association.

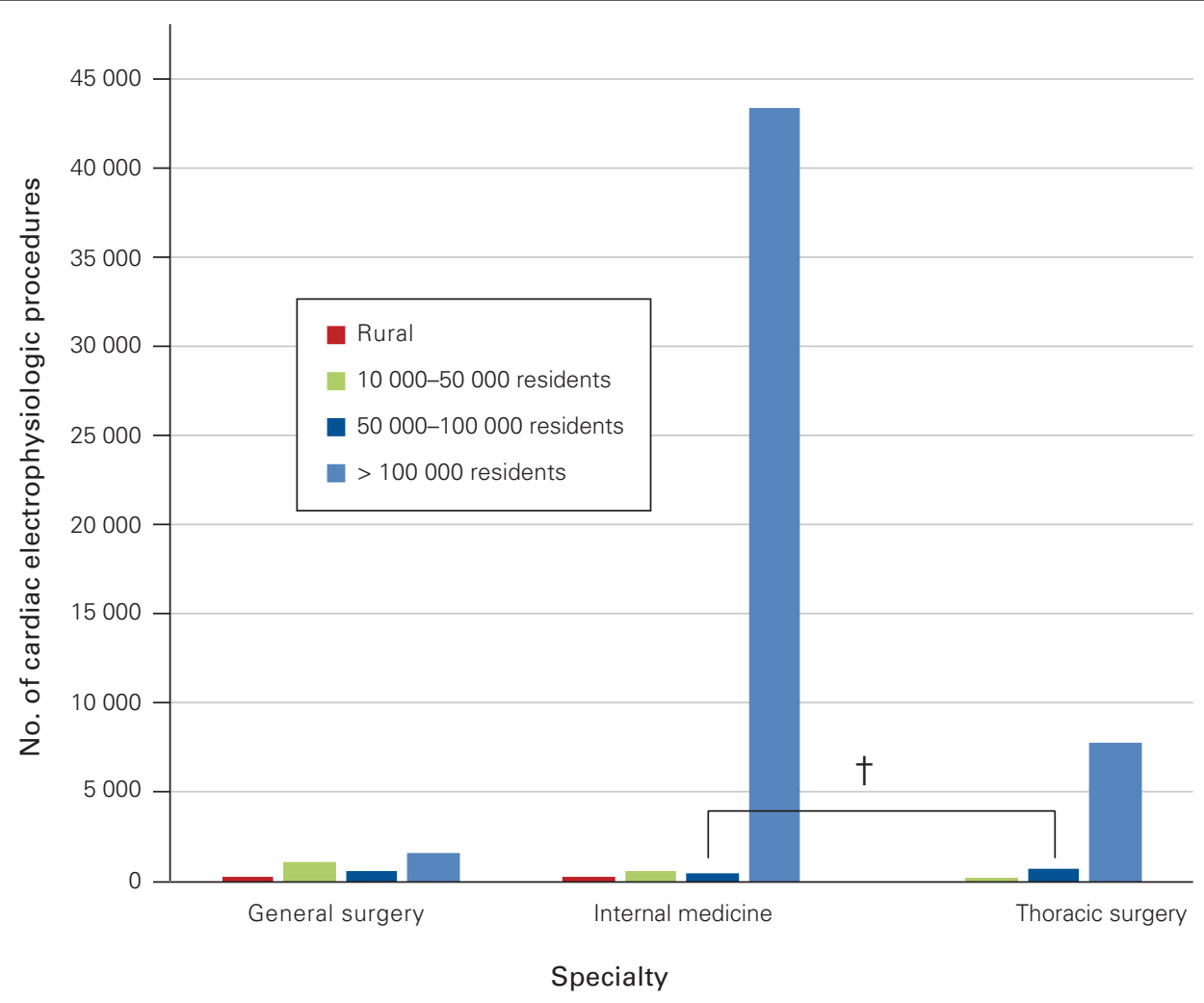

Fig. 6. Number of cardiac electrophysiologic (pacemaker) procedures performed by general surgeons, internal medicine specialists and thoracic surgeons in 2015/16, by community category. ${ }^{*}$ Moderate association; †strong association. 
The majority of these other services were provided by obstetricians, with an increasing number of general practitioners providing these services in smaller communities. The proportion of sterilizations performed by general surgeons, general practicioners and obstetricians varied significantly by community size $(p<0.0001$, Cramer $V=0.37$ strong), except for general surgery and general practice in communities with populations between 50000 and 100000 $(p=0.38)$ and greater than $100000(p=0.024)$. The proportion of cesarean deliveries performed by specialties varied significantly by community size $(p<0.001$, Cramer $V=$ 0.41 very strong). Figure 7 and Figure 8 show the number of cesarean deliveries and female sterilizations by specialty and community size, with moderate $(\varphi=0.20-0.29)$ to very strong $(\varphi=0.35-0.40)$ associations between the proportions of procedures performed by specialty.

\section{Vasectomy}

Most vasectomies were performed by general practitioners; however, in rural communities, general surgeons performed a comparable number of vasectomies to general practitioners and more than urologists. The proportion of vasectomies performed by each type of specialist differed signifcantly by community size $(p<0.0001$, Cramer $V=$ 0.30 strong), with the exception of the proportions of procedures performed by general surgeons and urologists in communities with populations between 50000 and $100000(p=0.511)$. Figure 9 shows the number of vasectomies by specialty and community size, with moderate $(\varphi=0.20-0.29)$ to very strong $(\varphi=0.35-0.40)$ associations between the proportions of procedures performed by specialty.

\section{Discussion}

Defining the scope of practice of a general surgeon is a complex undertaking. Although it may not be possible to achieve an all-encompassing definition of general surgery, our study helps provide the framework to understand the demographic characteristics and practice patterns of general surgeons in different settings across Canadian health care systems.

Most general surgeons were male, were aged 35-54 years, had trained in Canada and served communities with populations greater than 100000 . Nineteen percent of Canadians live in rural areas; only $7 \%$ of general surgeons practise in rural communities and $14 \%$ practise in communities with populations between 10000 and $50000 .{ }^{24}$ Similarly, in the United States approximately $10 \%$ of general surgeons practise in rural areas and the mean ages of physicians in rural areas are increasing. ${ }^{25}$ Rural general surgeons in the US are also more likely to be older men. ${ }^{26}$ In our study, rural communities were significantly more likely to have surgeons who were international medical graduates or who

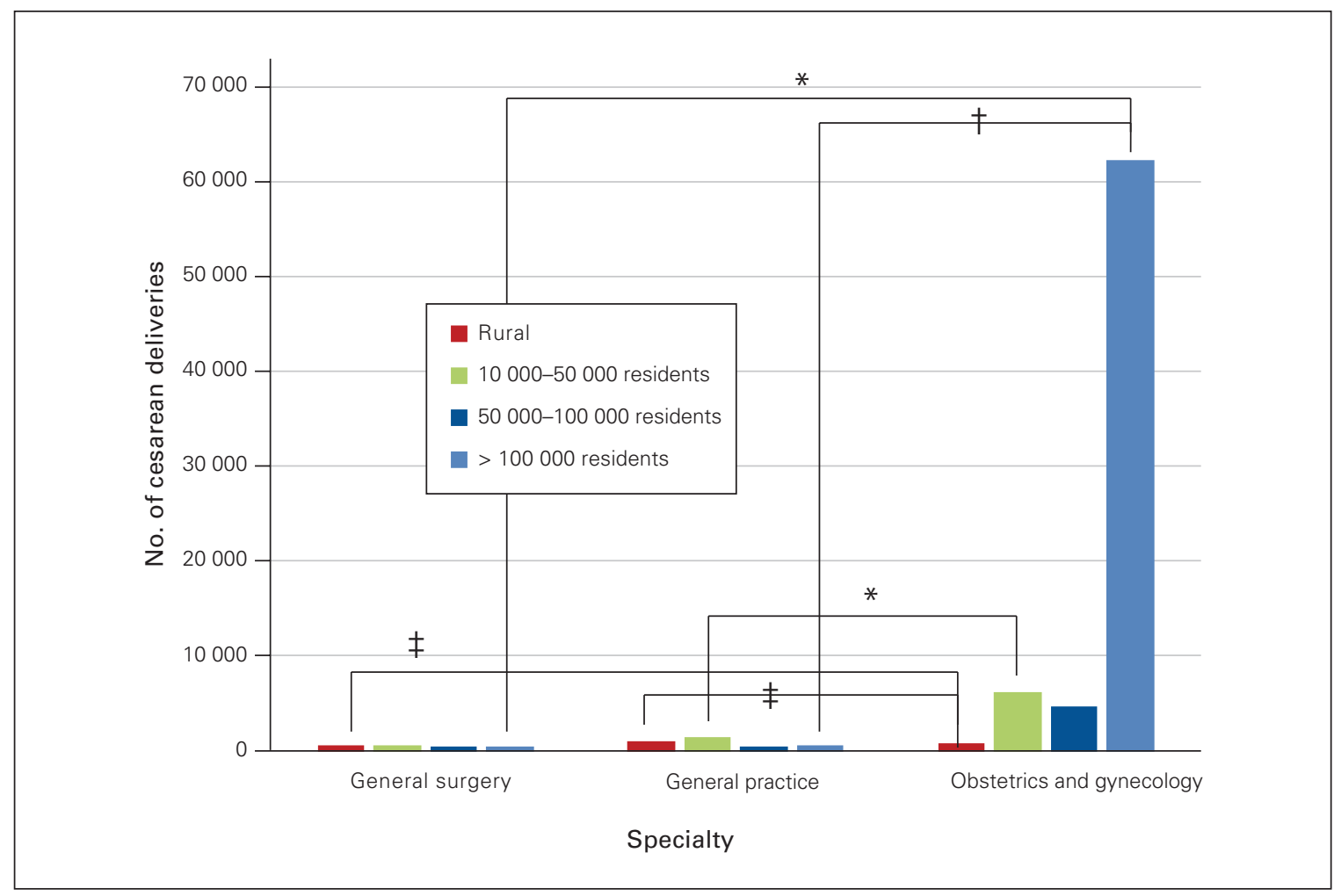

Fig. 7. Number of cesarean deliveries performed by general surgeons, general practitioners and obstetriciangynecologists in 2015/16, by community category. *Moderate association; †strong association; ¥very strong association. 


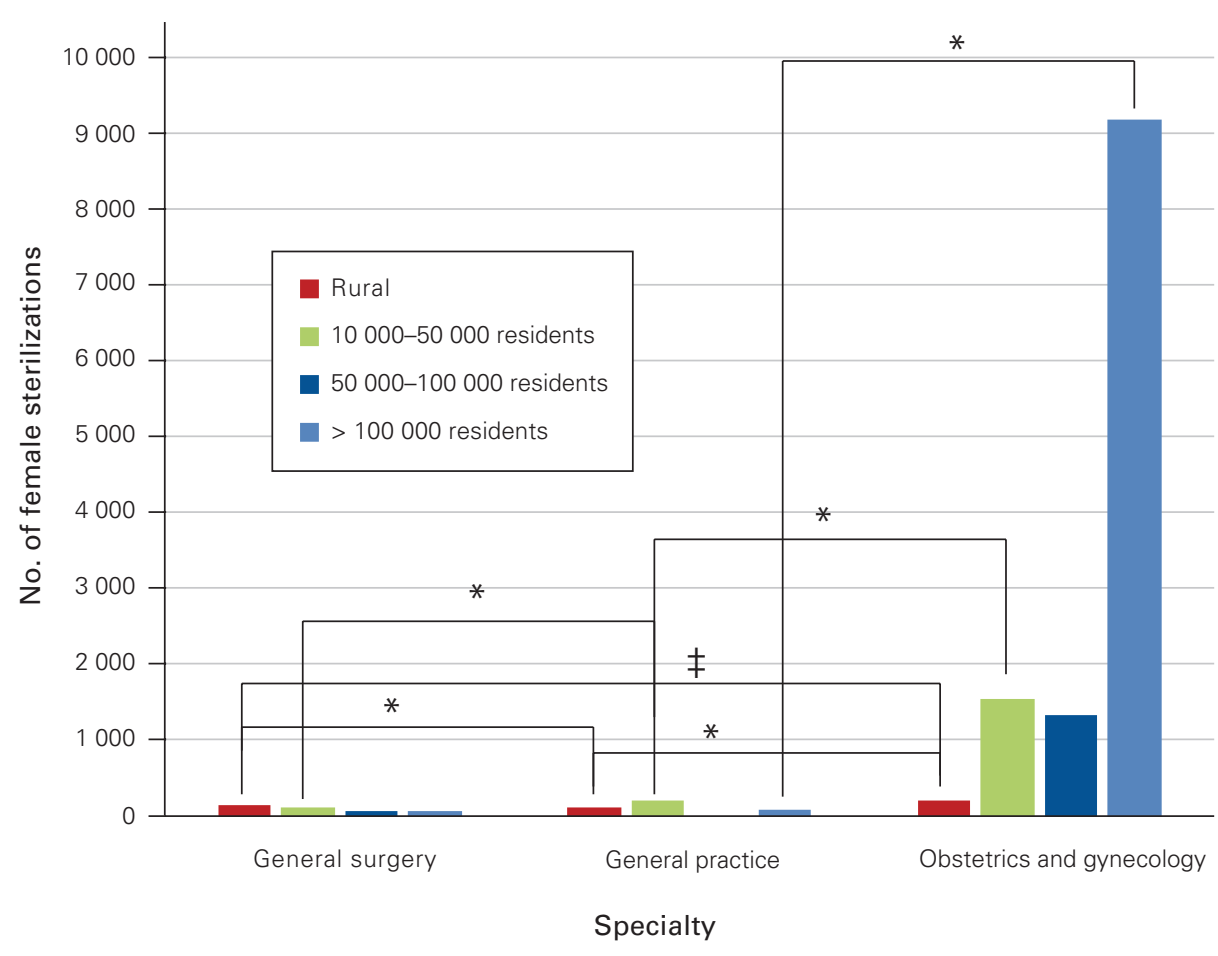

Fig. 8. Number of female sterilizations performed by general surgeons, general practitioners and obstetriciangynecologists in 2015/16, by community category. *Moderate association; ¥very strong association.

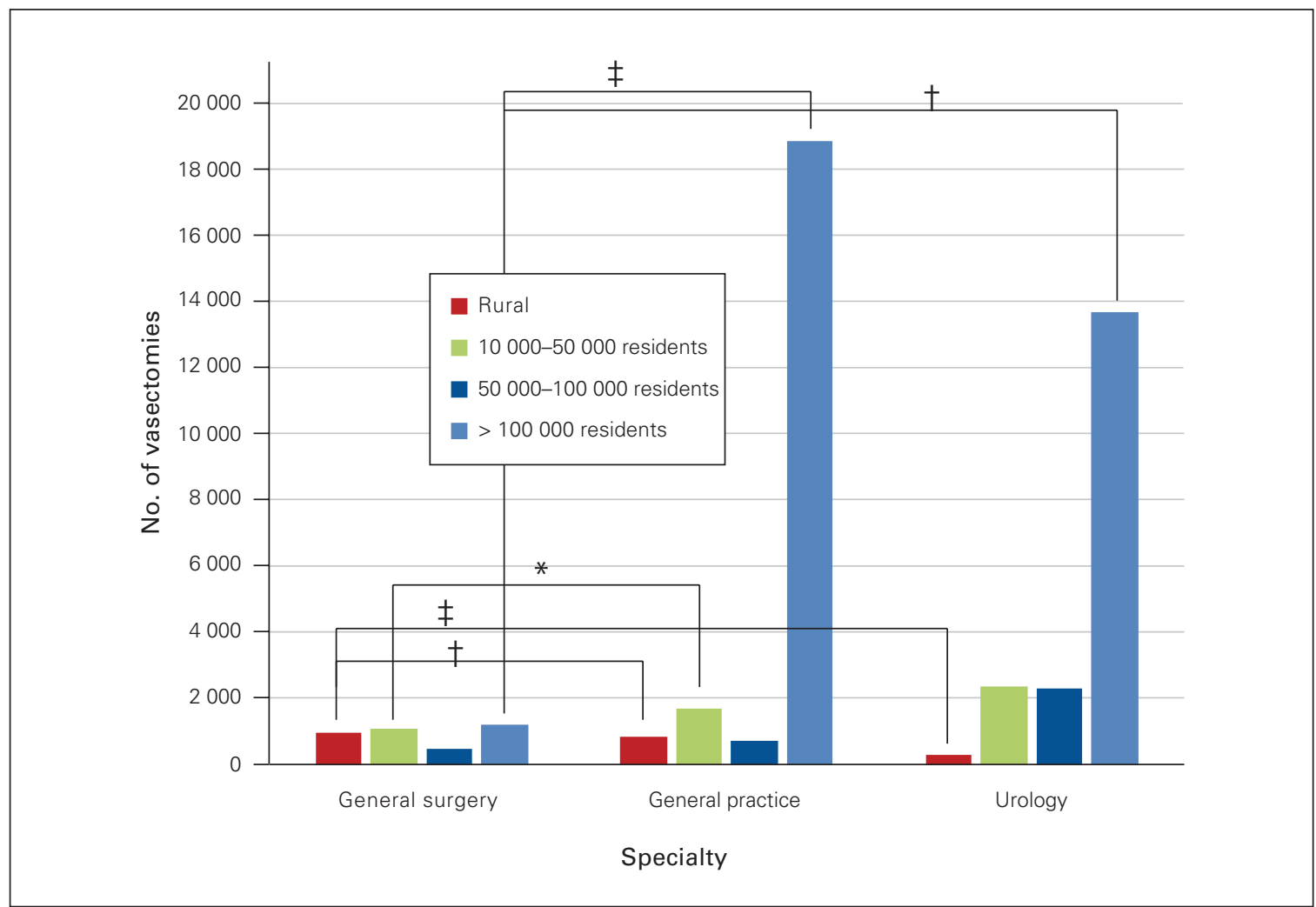

Fig. 9. Number of vasectomies performed by general surgeons, general practitioners and urologists in 2015/16, by community category. ${ }^{*}$ Moderate association; †strong association; ¥very strong association. 
were older than 65 years of age than communities with populations greater than 100000 . International medical graduates undertake postgraduate training outside of Canada or the US but are certified by the Royal College to meet the same standards as surgeons trained in Canada. Considering the proportion of surgeons 65 years of age in rural areas, there are comparatively fewer younger surgeons $(<35 \mathrm{yr})$ active in those regions. The recruitment and retention of newly graduated surgeons should be prioritized to ensure that quality care remains available to all Canadians, especially as senior surgeons retire. Strategies to recruit and retain rural physicians that have been discusseed in the literature include improving exposure to rural practice in medical school and residency; providing financial incentives for rural practice; establishing support, mentoring and consultation services for rural physicians; funding ongoing medical education opportunities, return for service and loan repayment programs for rural physicians; and providing provisional licensing for international medical graduates willing to practise in rural communities. ${ }^{27-31}$

Limitations to specialist employment in Canada, including in general surgery, were recently identified by the Royal College and include the availability of too few positions, poor access to job listings, graduates' desire or need to stay near family, the need for spousal employment, lack of availability of resources, and delayed retirement of practising physicians. ${ }^{32}$ This report also identified that $21 \%$ of graduates are not interested in practising in a rural area, which may be a result of the above factors, personal preference or the lack of opportunity to practise specific subspecialty skills gained in fellowship. Interestingly, the pursuit of subspecialty training to improve perceived hireability in a challenging job market may result in graduates then pursuing only jobs specific to their subspecialty rather than pursuing generalist careers, including in rural surgery. ${ }^{32}$ As a result, this inadvertent credential creep may contribute to further decreasing interest in rural careers. Encouraging residents to pursue exposure to rural practice and enhanced skills opportunities during training, as well as promoting rural generalism as a viable and respectable career path, is an important component of sustaining access to full-service rural general surgery in Canada. Providing flexible training opportunities for residents, as well as opportunities for transition to practice mentorship from retiring surgeons, can also support the entry of new graduates into rural practice.

The most commonly performed surgeries by general surgeons in Canada included hernia repairs, gallbladder and biliary tree procedures, excision of skin tumours, colon and intestine resections and breast surgery. American data also demonstrated that laparoscopic cholecystectomy, hernia repair, endoscopy, breast surgery, appendectomy and colon resection were the most commonly performed procedures among rural surgeons. ${ }^{33}$ It is interesting that the distribution of colorectal surgeries was similar to that of appendectomies, hernia repairs and gallbladder procedures regardless of community size. This underscores how fundamental these procedures are to the practice of general surgery.

It has been well documented that surgeons working in smaller communities require exposure to procedures associated with surgical specialties outside of general surgery. ${ }^{34}$ Specific procedures that are not listed in the Royal College training objectives but that were regularly performed by general surgeons include pacemaker insertions, vasectomies and cesarean deliveries. Tonsillectomy, fracture management and female sterilization were also regularly performed by rural surgeons. Surgeons in smaller communities performed a large volume of integumentary procedures and could benefit from training in complex wound closure and flap reconstruction.

Perhaps the single most important procedure omitted from the Royal College training objectives is cesarean delivery. New graduates may not be qualified to work in rural areas because they lack training in this procedure. The availability of emergency cesarean delivery is essential to rural Canadians and is often the key factor determining whether a patient can deliver close to home rather than being transported to a larger centre in their peripartum period. Acquisition of cesarean delivery and other subspecialty skills in residency training is largely dependent on trainees intentionally seeking out elective experiences, especially as residency programs across Canada can vary. Training programs should ensure opportunities exist for aspiring rural surgeons to obtain these skills. Such opportunities could include an elective or mandatory rotation early in residency at a rural site; such sites are known to have high case volumes of minor procedures and endoscopy..$^{35}$ Some residency programs have opted for either offering a rural general surgery residency or ensuring that the majority of a resident's rotations take place at a rural or community site. ${ }^{36}$

Gastroscopy and colonoscopy remain essential components of a general surgeon's practice and were the most commonly performed procedures across all communities. Sigmoidoscopy appears to be primarily performed in communities with more than 100000 residents. Prior studies show that screening colonoscopies are performed in nearly equal numbers by general surgeons and gastroenterologists across Canada, but rural areas are predominantly served by general surgeons. ${ }^{37}$ Internal medicine specialists provided the majority of gastroscopies in populations greater than 100000 , but smaller communities were serviced almost exclusively by general surgeons. Surgical residents planning to enter rural practice should understand that endoscopy will be a large part of their practice and they may require additional endoscopy training in residency.

General practitioners, some with enhanced surgical skills training, also provide endoscopy services to small communities, although at much lower numbers than surgeons and internists. The growing role of general practitioners 
with enhanced surgical skills practising in rural Western Canada has been previously described ${ }^{15}$ and includes a wide variety of procedures, such as hernia repair, appendectomy, treatment of acute ovarian and testicular disease, endoscopy, treatment of gastrointestinal bleeding, treatment of benign perianal disease, cesarean delivery, treatment of ectopic pregnancy, hysteroscopy, integumentary lesion resection, male and female sterilization, tonsillectomy, and carpal tunnel and trigger finger release. These skills are taught in a 12-month postgraduate training program for general practitioners who practise in communities generally too small to support a full-time general surgeon. ${ }^{15}$ It is interesting that surgeries on the small intestine, colon and rectum are being performed by general practitioners. Examining the definitions of these categories may partially explain this finding. It is conceivable that in rare situations a family physician with enhanced surgical skills is required to perform a bowel resection during an inguinal hernia repair or may electively perform minor procedures on perirectal tissue. It is also possible that some physicians have completed multiple residency programs or international medical graduates without Canadian certification may have been grandfathered into situations where they perform more complex procedures than typical general practitioners. Although the training of general practitioners in surgical skills has been controversial, ${ }^{38}$ it is undeniably providing a valuable service to rural Canadians. ${ }^{15}$ Critics of this model have argued that rural communities would be better served by broadly trained general surgeons and that the transition to competencybased residency training should help provide adequate surgical care for rural Canadians. ${ }^{38}$

\section{Limitations}

The scope of this study is broad, and several limitations need to be considered. Procedural data obtained from CIHI were grouped into general categories; it was not possible to break the categories down into specific procedures (i.e., all gallbladder and biliary tree procedures were grouped together; it was not possible to tease out cholecystectomy or distinguish between procedures of differing complexities). Some CIHI definitions were either too broad or were thought to be inaccurate and these definitions were excluded (i.e., "other respiratory," which was thought to include thoracotomy). Data for some procedures of interest, such as burr hole, thyroidectomy and parathyroidectomy, carpal tunnel release, splenectomy and trauma management, were not available. If a procedure was performed fewer than 5 times, we reported the count as "less than 5" rather than reporting the specific value (to ensure anonymity), and a conservative estimate of 1 was used in analysis. All data were obtained from physicians' billing, which may be prone to error and bias, and alternative forms of reimbursement, such as salary, private billing, or capitation, were excluded. Practice locations were determined from the postal code of physicians' primary practice location and thus could underrepresent rural care provided by locums who primarily practise in urban centres. Physicians who practised in more than 1 province were accounted for in the data. Data were obtained from 8 provinces, which provided an excellent overview of practice in Canada, but the data set cannot be considered complete without factoring in the remaining provinces and territories, many of which had available data but were limited by small sample sizes and could not be included because of deidentification and privacy issues. This could result in underrepresentation of the care received by patients living in remote and northern areas. An analysis by province was also not possible from the available CIHI data. Physicians may have been excluded from the analysis as they were classified by their payment plan specialty (i.e., thoracic surgeons, who may have a split practice or perform on-call general surgery cases).

\section{ConcLusion}

To our knowledge, this is the first Canadian study to quantify the practice of general surgeons at this scale. Canadian general surgeons are a diverse group who provide a wide array of surgical services. Rural communities were more likely to be served by older and internationally trained surgeons. Practice patterns varied by community size. Surgeons practising in rural and small communities require proficiency in skills not routinely taught in general surgery residency. Training opportunities to acquire these skills need to be made available to prepare surgeons for their career in meeting the care needs of Canadians. The Royal College objectives should be reviewed to ensure that competencies, opportunities to acquire and evaluate skills, and licensure for procedures such as cesarean delivery can be available for future rural general surgeons.

Acknowledgement: The authors acknowledge the Royal College of Physicians and Surgeons of Canada for their support in securing data and developing the study methodology.

Affiliations: From the Division of General Surgery, McMaster University, Hamilton, Ont. (Schroeder); the Cumming School of Medicine, University of Calgary, Calgary, Alta. (Sheppard); the Canadian Association of General Surgeons, Ottawa, Ont. (Wilson); the Division of General Surgery, University of Ottawa, Ottawa, Ont. (Champion); the Royal College of Physicians and Surgeons of Canada, Ottawa, Ont. (DiMillo); the Northern Ontario School of Medicine, Huntsville District Memorial Hospital, Huntsville, Ont. (Kirkpatrick); the University of British Columbia, Shuswap Lake General Hospital, Salmon Arm, B.C. (Hiscock); the Department of Surgery, University of Saskatchewan, Victoria Hospital, Prince Albert, Sask. (Friesen); the Department of Surgery, Charles S. Curtis Memorial Hospital, Labrador-Grenfell Health, St. Anthony, Nfld. (Smithson); and the Department of Surgery, University of Alberta, Queen Elizabeth II Hospital, Grande Prairie, Alta. (Miles).

Competing interests: T. Schroeder, D. Wilson, C. Champion, R. Kirkpatrick, S. Hiscock, R. Friesen, L. Smithson and P. Miles are members of the Rural Surgery Committee of the Canadian Association of General Surgeons. No other competing interests were declared. 
Contributors: T. Schroeder, C. Sheppard, C. Champion, R. Kirkpatrick, S. Hiscock and P. Miles designed the study. T. Schroeder, D. Wilson, S. DiMillo and P. Miles acquired the data, which T. Schroeder, C. Sheppard, C. Champion, S. DiMillo, R. Kirkpatrick, S. Hiscock, R. Friesen, L. Smithson and P. Miles analyzed. All authors critically revised the manuscript and gave final approval of the version to be published.

Disclaimer: The views expressed in this article do not necessarily respresent the official position of the Royal College of Physicians and Surgeons of Canada or the Canadian Association of General Surgeons. Parts of this material are based on data and information provided by the Canadian Institute for Health Information. However, the analyses, conclusions, opinions and statements herein are those of the authors and not those of the Canadian Institute for Health Information.

\section{References}

1. Decker MR, Bronson NW, Greenberg CC, et al. The general surgery job market: analysis of current demand for general surgeons and their specialized skills. 7 Am Coll Surg 2013;217:1133-9.

2. Royal College of Physicians and Surgeons of Canada. Objectives of training in the specialty of general surgery. Ottawa: Royal College of Physicians and Surgeons of Canada; 2017.

3. Webber EM, Ronson AR, Gorman LJ, et al. The future of general surgery: evolving to meet a changing practice. 7 Surg Educ 2016; 73:496-503.

4. De Gara C, Birkmeyer J, Bohnen J, et al. Canadian Association of University Surgeons' Annual Symposium: W(h)ither generalism(?). Can 7 Surg 2010;53:196-201.

5. Cofer JB, Burns RP. The developing crisis in the national general surgery workforce. 7 Am Coll Surg 2008;206:790-5, discussion 795-7.

6. Humber N, Frecker T. Rural surgery in British Columbia: Is there anybody out there? Can 7 Surg 2008;51:179-84.

7. Urbach DR, Croxford R, MacCallum NL, et al. How are volumeoutcome associations related to models of health care funding and delivery? A comparison of the United States and Canada. World 7 Surg 2005;29:1230-3.

8. Finlayson SR, Birkmeyer JD, Tosteson AN et al. Patient preferences for location of care: implications for regionalization. Med Care 1999;37:204-9.

9. Stewart GD, Long G, Tulloh BR. Surgical service centralisation in Australia versus choice and quality of life for rural patients. Med $\mathcal{F}$ Aust 2006;185:162-3.

10. Shively EH, Shively SA. Threats to rural surgery. Am 7 Surg 2005;190:200-5.

11. Jarman BT, Cogbill TH, Mathiason MA, et al. Factors correlated with surgery resident choice to practice general surgery in a rural area. 7 Surg Educ 2009;66:319-24.

12. Ryan JP, Borgert AJ, Kallies KJ, et al. Can rural minimally invasive surgery fellowships provide operative experience similar to urban programs? 7 Surg Educ 2016;73:793-8.

13. Khubchandani JA, Shen C, Ayturk D et al. Disparities in access to emergency general surgery care in the United States. Surgery 2018; $163: 243-50$.

14. Fleet R, Audette LD, Marcoux J et al. Comparison of access to services in rural emergency departments in Quebec and British Columbia. CFEM 2014;16:437-48.

15. Caron N, Iglesias S, Friesen R, et al. A proposal for the curriculum and evaluation for training rural family physicians in enhanced surgical skills. Can f Surg 2015;58:419-22.

16. Decker MR, Dodgion CM, Kwok AC, et al. Specialization and the current practices of general surgeons. 7 Am Coll Surg 2014;218:8-15.

17. VanBibber M, Zuckerman RS, Finlayson SRG. Rural versus urban inpatient case-mix differences in the US. 7 Am Coll Surg 2006;203:812-6.
18. Doty B, Heneghan S, Gold M, et al. Is a broadly based surgical residency program more likely to place graduates in rural practice? World F Surg 2006;30:2089-93.

19. Stain SC, Cogbill TH, Ellison EC, et al. Surgical training models: a new vision. Broad-based general surgery and rural general surgery training. Curr Probl Surg 2012;49:565-623.

20. Sticca RP, Mullin BC, Harris JD, et al. Surgical specialty procedures in rural surgery practices: implications for rural surgery training. $\mathrm{Am}$ 7 Surg 2012;204:1007-12, discussion 1012-3.

21. Pollett WG, Dicks E. Training of Canadian general surgeons: Are they really prepared? CAGS questionnaire on surgical training. Can $\mathcal{f}$ Surg 2005;48:219-24.

22. Gillman LM, Vergis A. General surgery graduates may be ill prepared to enter rural or community surgical practice. Am 7 Surg 2013;205:752-7.

23. Canadian Medical Association. General surgery profile. Ottawa: Canadian Medical Association; 2018 Aug. Available: https://www. cma.ca/Assets/assets-library/document/en/advocacy/profiles/general -surgery-e.pdf (accessed 2019 Nov. 22).

24. Statistics Canada. Canada's rural population since 1851. Ottawa: Statistics Canada; 2018 Jul. 23. Available: https://www12.statcan.gc.ca/ census-recensement/2011/as-sa/98-310-x/98-310-x2011003_2-eng.cfm (accessed 2019 Nov. 22).

25. Breon TA, Scott-Conner CE, Tracy RD. Spectrum of general surgery in rural Iowa. Curr Surg 2003;60:94-9.

26. Lynge DC. Rural general surgeons: manpower and demographics. Surg Endosc 2008;22:1593-4.

27. Parlier AB, Galvin SL, Thach S, et al. The road to rural primary care: a narrative review of factors that help develop, recruit, and retain rural primary care physicians. Acad Med 2018;93:130-40.

28. MacQueen IT, Maggard-Gibbons M, Capra G, et al. Recruiting rural healthcare providers today: a systematic review of training program success and determinants of geographic choices. 7 Gen Intern Med 2018;33:191-9.

29. Glenn IC, Bruns NE, Hayek D, et al. Rural surgeons would embrace surgical telementoring for help with difficult cases and acquisition of new skills. Surg Endosc 2017;31:1264-8.

30. Mathews M, Heath SL, Neufeld SM, et al. Evaluation of physician return-for-service agreements in Newfoundland and Labrador. Healthc Policy 2013;8:42-56.

31. Fleming P, Mathews M. Retention of specialist physicians in Newfoundland and Labrador. Open Med 2012;6:e1-9.

32. Frechette D, Shrichand A, Manogaran M. Employment patterns of Canada's newly certified medical specialists: findings from the Royal College Employment Study. Ottawa: Royal College of Physicians and Surgeons of Canada; 2019.

33. Halverson AL, Hughes TG, Borgstrom DC, et al. What surgical skills rural surgeons need to master. 7 Am Coll Surg 2013; 217:919-23.

34. Deal SB, Cook MR, Hughes D, et al. Training for a career in rural and nonmetropolitan surgery - a practical needs assessment. 7 Surg Educ 2018.

35. Harris JD, Hosford CC, Sticca RP. A comprehensive analysis of surgical procedures in rural surgery practices. Am 7 Surg 2010;200:8205.

36. Mercier PJ, Skube SJ, Leonard SL, et al. Creating a rural surgery track and a review of rural surgery training programs. 7 Surg Educ 2019;76:459-68.

37. Doumouras AG, Anvari S, Cadeddu M, et al. Geographic variation in the provider of screening colonoscopy in Canada: a populationbased cohort study. CMA7 Open 2018;6:E126-31.

38. Vinden C, Ott MC. GPs with enhanced surgical skills: a questionable solution for remote surgical services. Can 7 Surg 2015;58:369-71. 